International Journal of Modern Physics D

Vol. 14, No. 10 (2005) 1837

(C) World Scientific Publishing Company

ERRATUM

\title{
INFLUENCES OF PHYSICAL PARAMETERS OF NEUTRON STARS ON THE IR POSITIONS ON THE $P-\dot{P}$ DIAGRAM
}

[INT. J. MOD. PHYS. D, Vol. 14, No. 8 (2005) 1465-1471]

OKTAY H. GUSEINOV

Akdeniz University, Department of Physics, Antalya, Turkey ohuseyin@akdeniz.edu.tr

AŞKIN ANKAY

TÜBITTAK Feza Gürsey Institute, Çengelköy, Istanbul, Turkey

and

Boğaziçi University, Department of Physics, Istanbul, Turkey askin@gursey.gov.tr

SEVINÇ O. TAGIEVA

Academy of Science, Physics Institute, Baku 370143, Azerbaijan Republic physic@lan.ab.az

The title should read as:

\section{INFLUENCES OF PHYSICAL PARAMETERS OF NEUTRON STARS ON THE POSITIONS OF THEM ON THE $P-\dot{P}$ DIAGRAM}

The publisher apologizes for the error made. 